\title{
Implicaçóes da reforma trabalhista na alimentação dos trabalhadores
} Implications of labor reform on workers' feeding

\section{| ${ }^{1}$ Alisson Diego Machado |}

1 Faculdade de Medicina, Universidade de São Paulo. São Paulo-SP, Brasil (alissondiegomachado@hotmail.com). ORCID: 0000-0002-1564-5405

\section{Recebido em: 10/08/2017}

Aprovado em: 21/02/2018

Revisado em: 22/03/2018

DOI: http://dx.doi.org/10.1590/S0103-73312018280203

Devido à crise econômica enfrentada pelo Brasil, o governo de Michel Temer tem adotado diversas medidas em função de uma suposta retomada da economia. Uma dessas medidas é a tratada pela Lei no 13.467 (BRASIL, 2017), que tramitou no Senado Federal como Projeto de Lei da Câmara (PLC) no 38/2017, conhecida como reforma trabalhista.

Embora a reforma trabalhista possua inúmeros tópicos que podem ser discutidos, neste artigo será abordada apenas a possibilidade da redução do intervalo intrajornada. A referida Lei altera a Consolidação das Leis do Trabalho (CLT) em diversos pontos, sendo um deles em seu Art. 611-A, estabelecendo que a convenção ou acordo coletivo de trabalho tenham força de lei quando dispuserem sobre determinados pontos, como a possibilidade de redução do intervalo intrajornada, desde que seja garantido um limite mínimo de trinta minutos para jornadas superiores a seis horas (BRASIL, 2017).

A CLT estabelece em seu Art. 71 que, para trabalhos contínuos cuja duração exceda seis horas, seja obrigatória a concessão de um intervalo intrajornada de no mínimo uma hora para repouso e alimentaçáo e, em seu parágrafo $1^{\circ}$, determina a obrigatoriedade de um intervalo de quinze minutos para jornadas entre quatro e seis 
horas. A redução ou fracionamento desse intervalo é permitida desde que prevista em convenção ou acordo coletivo de trabalho apenas para determinadas categorias, como motoristas, cobradores e algumas atividades do setor de transporte, de acordo com seu parágrafo $5^{\circ}$ (BRASIL, 1943).

Assim, embora a alteração do intervalo intrajornada não seja uma obrigatoriedade, tampouco garante que seja estabelecido um intervalo em que realmente seja possível que o trabalhador possa repousar e se alimentar adequadamente. Em relação à alimentação, é importante considerar que o intervalo intrajornada engloba não apenas o tempo para o consumo de alimentos, mas também o deslocamento até o local onde a refeição será realizada e os tempos de espera, atendimento e pagamento e, certamente, 30 minutos podem não ser suficientes para tal, o que pode fazer com que o consumo de fast food e de alimentos prontos, como salgados e sanduíches, seja uma alternativa decorrente da redução do intervalo.

Segundo o Inquérito Nacional de Alimentação (INA), 42,6\% da população adulta brasileira realizava refeiçôes fora do domicílio em 2008-2009, sendo que a maior parte (40\%) do consumo fora do lar ocorreu entre 12 e 14 horas (BEZERRA et al., 2013), período em que geralmente os brasileiros realizam o almoço. Ainda de acordo com o estudo, os grupos de alimentos proporcionalmente mais consumidos fora do domicílio do que no lar foram os salgadinhos fritos e assados, pizza, sanduíches e refrigerantes, independentemente de sexo e nas áreas urbana e rural (BEZERRA et al., 2013). Os dados do INA demonstraram que os locais em que a população mais consumiu alimentos fora do domicílio foram as lanchonetes $(16,9 \%)$ e os restaurantes $(16,4 \%)$. Nas lanchonetes, os itens mais consumidos foram salgadinhos $(27,3 \%)$, refrigerante $(24,0 \%)$, fast food $(23,4 \%)$ e doces $(23,0 \%)$, enquanto nos restaurantes foram refeições (66,7\%), bebidas alcoólicas $(20,4 \%)$ e refrigerante (16,9\%) (BEZERRA et al., 2017). Embora o estudo não tenha indicado os locais de consumo de acordo com o horário, é possível pressupor que, como o almoço representou $40 \%$ do que foi consumido fora do lar, uma parte considerável das refeições tenha sido realizada nesses locais no horário de almoço.

Em um estudo feito em Campinas-SP, verificou-se que 52,0\% da amostra de estudo se alimentava com frequência regular, e 18,8\%, frequentemente, em comércios do tipo fast food, bares, lanchonetes e em barracas, demonstrando que estabelecimentos que comercializam fast food e preparaçóes prontas são procurados pela população para realizarem o almoço. Além disso, o tempo de atendimento 
foi considerado muito importante e muitíssimo importante por $64,0 \%$ dos participantes como um fator que influencia a escolha dos estabelecimentos (SANCHES; SALAY, 2011).

Estudos demonstraram que as refeiçóes efetivadas fora do lar, geralmente, contêm mais açúcares e gorduras e possuem menor qualidade nutricional em relação às refeiçôes realizadas no ambiente doméstico (BANDONI et al., 2013; GORGULHO; FISBERG; MARCHIONI, 2013). Tais resultados podem sugerir que a alimentação fora do lar possa estar associada ao excesso de peso e, de fato, na Pesquisa de Orçamentos Familiares 2002-2003, o consumo de alimentos fora do ambiente doméstico se associou positivamente ao sobrepeso e à obesidade em homens, bem como a ingestão de refrigerante (BEZERRA; SICHIERI, 2009). De acordo com o estudo de revisão realizado por Bezerra, Curioni e Sichieri (2012), em grande parte das publicaçôes avaliadas houve associação positiva entre a alimentação fora do domicílio e o peso corporal.

Esses estudos demonstram que a alimentação fora do lar necessita ser melhorada, o que torna ainda mais preocupante a possibilidade da redução do intervalo intrajornada e suas implicaçóes na alimentação dos trabalhadores e, consequentemente, no estado nutricional destes, ainda mais se levando em consideração o aumento constante da prevalência de sobrepeso e obesidade no país (MALTA et al., 2014).

Nos casos em que houver redução do intervalo intrajornada, seria ideal que as empresas oferecessem a alimentaçáo aos seus funcionários no próprio local de trabalho ou que, ao menos, disponibilizassem refeitório para que os trabalhadores pudessem levar suas refeiçôes do lar e se alimentarem adequadamente.

É importante que se leve em consideração que a escolha alimentar está associada a outros fatores, como palatabilidade, disponibilidade e preço. Contudo, é igualmente importante ter em conta que a promoção da saúde vai além das escolhas e práticas individuais, devendo ser garantida também por meio de condiçóes que possibilitem que se adote um estilo de vida saudável (ALVES; JAIME, 2014) e, nesse ponto, a redução do intervalo intrajornada pode dificultar tal adoção.

\section{Referências}

ALVES, K. P. S.; JAIME, P. C. A Política Nacional de Alimentação e Nutrição e seu diálogo com a Política Nacional de Segurança Alimentar e Nutricional. Ciência \& Saúde Coletiva. Rio de Janeiro, v. 19, n. 11, p. 4.331-4.340, 2014. 
BANDONI, D. H. et al. Eating out or in from home: analyzing the quality of meal according eating locations. Revista de Nutrição. Campinas, v. 26, n. 6, p. 625-632, 2013.

BEZERRA, I. N.; CURIONI, C.; SICHIERI, R. Association between eating out of home and body weight. Nutrition Reviews. Oxford, v. 70, n. 2, p. 65-79, 2012.

BEZERRA, I. N. et al. Consumo de alimentos fora do lar no Brasil segundo locais de aquisição. Revista de Saúde Pública. São Paulo, v. 51, n. 15, 2017.

BEZERRA, I. N.; SICHIERI, R. Eating out of home and obesity: a Brazilian nationwide survey. Public Health Nutrition. Cambridge, v. 12, n. 11, p. 2.037-2.043, 2009.

BEZERRA, I. N. et al. Consumo de alimentos fora do domicílio no Brasil. Revista de Saúde Pública. São Paulo, v. 47, supl. 1, p. 200S-211S, 2013.

BRASIL. Decreto-Lei $n^{\circ}$ 5.452, de $1^{\circ}$ de maio de 1943. Aprova a Consolidação das Leis do Trabalho. Rio de Janeiro, RJ: Diário Oficial da União, 9 ago. 1943. Seção 1, p. 1.

BRASIL. Lei no 13.467, de 13 de julho de 2017. Altera a Consolidação das Leis do Trabalho (CLT), aprovada pelo Decreto-Lei no 5.452 , de $1^{\circ}$ de maio de 1943 , e as Leis $n^{\circ} \mathrm{s} 6.019$, de 3 de janeiro de 1974, 8.036, de 11 de maio de 1990, e 8.212, de 24 de julho de 1991, a fim de adequar a legislação às novas relações de trabalho. Brasília, DF: Diário Oficial da União, 14 jul. 2017. Seção 1, p. 1.

GORGUlHO, B. M.; FISBERG, R. M.; MARCHIONI, D. M. Nutritional quality of major meals consumed away from home in Brazil and its association with the overall diet quality. Preventive Medicine. Amsterdam, v. 57, n. 2, p. 98-101, 2013.

MALTA, D. C. et al. Evolução anual da prevalência de excesso de peso e obesidade em adultos nas capitais dos 26 estados brasileiros e no Distrito Federal entre 2006 e 2012. Revista Brasileira de Epidemiologia. São Paulo, v. 17, supl. 1, p. 267-276, 2014.

SANCHES, M.; SALAY, E. Alimentação fora do domicílio de consumidores do município de Campinas, São Paulo. Revista de Nutrição. Campinas, v. 24, n. 2, p. 295-304, 2011. 